\title{
SECONDARY SCHOOL TEACHER SUPPORT AND TRAINING FOR ONLINE TEACHING DURING THE COVID-19 PANDEMIC
}

\author{
Cecilia Fissore, Marina Marchisio, Sergio Rabellino, University of Torino, Italy
}

\section{Abstract}

In Italy, due to the Covid-19 pandemic, all schools were closed on March 5, 2020 and it was mandatory to switch to "distance learning", in order not to interrupt the teaching continuity and to guarantee the right to education for all students. The Ministry of Education suggested several initiatives to teachers, including the PP\&S national project. In the paper we analyse why and how the PP\&S project, intended for teachers of secondary schools of the STEM disciplines but opened in the emergency to teachers of all disciplines, was able to provide much needed support and not only. Following this opening and the consequent registration of many new teachers, three different phases were carried out: an analysis phase of the teachers' needs for online teaching, a phase of support and initial help, and a training phase. The results show an extremely high participation of the teachers and a wide online collaboration. All the teachers of the PP\&S will certainly have an advantage in the post-covid teaching, since they can take advantage of the work done and the experience and skills gained in the past.

\section{Introduction}

In Italy, due to the Covid-19 pandemic, all schools were closed on March 5, 2020 and will not be reopened until after the end of this school year. After the lockdown of the schools and the suspension of face-to-face lessons, it was necessary to switch to "distance learning", in order not to interrupt the teaching continuity and to guarantee the right to education for all the students. Not many schools were prepared for this type of change. For example, because they did not adopt online teaching in normal teaching, teachers did not have the adequate digital skills and adequate computers, so teachers and students were not used to working in a Digital Learning Environment (DLE), a shared virtual space. Some schools chose to adopt a unified solution for all classes, while other schools gave teachers the opportunity to adopt the virtual learning environment that they considered most appropriate for their subject. After a reasoned and aware choice of the virtual learning environment to be used for online teaching, the teachers had to quickly learn how to use it and they had to transform the teaching practices that they would have carried out face- 
to-face into an online mode. The Ministry of Education created a site dedicated to distance learning, to globally distribute instructions to teachers and schools who had to activate some forms of distance learning and did not know which tools to choose and had no examples of activities to get inspiration from. In fact, according to the Ministerial Decree of 8 March 2020, each School Head was able to activate the distance teaching methods at his/her discretion and liking, for the entire duration of the suspension of educational activities in schools, with particular attention to specific needs of students with disabilities. This site (available at https://www.istruzione.it/coronavirus/didattica-a-distanza.html) offers a list of cooperation tools, exchange of good practices and twinning between schools, training webinars, multimedia content for study, certified platforms (also in accordance with the privacy protection regulations) for distance learning. Part of these tools can be used for free during the lockdown period thanks to specific protocols signed by the Ministry of Education. One of the proposed initiatives is the PP\&S national project (Barana et al., 2019). The PP\&S - "Problem Posing and Solving" - project (available at www.progettopps.it), headed by the Italian Ministry of Education, promotes since 2012 the training of teachers of secondary schools on innovative teaching methods, through the use of digital technologies, and on the creation of a culture of problem posing and problem solving, with the use of Information and Communication Technology (ICT). Teachers involved in the project learn how to use different kinds of digital tools and new methodologies, in order to enhance their daily didactic. The University of Turin is one of the partners of this project and hosts and maintain the IT infrastructure of the project. Initially, it was intended only for teachers of secondary schools of STEM disciplines but, during the emergency from Covid-19 the project, it was opened to teachers of secondary schools of all disciplines to support them in online teaching. The project also allows the enrolment of the entire school in order to facilitate teachers and students in the use of a single DLE. By enrolling in the project, totally free of charge, teachers have the possibility of having an integrated DLE for all the classes of students they need. Within it, students can be provided with multiple resources (interactive materials, links, videos, theoretical explanations, etc.) and numerous synchronous and asynchronous other online activities. The activities carried out by students can be evaluated, alone or in a group, and it is possible to monitor the students' actions on the platform and the learning objectives achieved. The teachers who were part of the PP\&S before the pandemic and the closure of schools were already using the digital environment integrated in their daily teaching. As a result, it was much easier for them to switch to distance learning. In their case, we believe that we can speak effectively of online teaching. After opening the project to teachers of all disciplines and the consequent registration of many new teachers (Table 1), the first step was to try to detect (through an optional questionnaire) the main needs of teachers for online teaching. For example, on the use of the virtual learning environment, on the activities and resources that can be used, on the assessment of students and on the monitoring of their platform 
activities. At the same time, special comments, suggestions and training needs were collected. This phase of needs analysis was followed by a support phase and a training phase for teachers, organized thanks to a group of expert teacher trainers who, from the beginning of the project, carry out face-to-face training activities and online training activities. The support phase, which took place in the first period of school lockdown, was characterized by individual synchronous online training meetings to give teachers a first basic training and to support them in the initial emergency and in the transition to online teaching. Compared to the online training meetings that took place regularly within the project, it was sufficient to increase the hours of training to be able to reach all the teachers who enrolled in the project from time to time and to be able to vary the topics of the training meetings while maintaining the basic training feature. In addition, all the teachers of the PP\&S could collaborate on the platform within the Community of the Teachers of the PP\&S to exchange tips, teaching practices and ideas, and they always had the support of the teacher trainers of the project, who were available through the Helpdesk service of the platform and through forums. In May, when most of the teachers had started teaching online with the students and had become familiar with the proposed tools, the training phase began. This phase, still ongoing, is characterized by an open vision to go beyond basic training. In this phase, teachers are offered advanced courses on online teaching, which also include activities to be carried out together with the students. This allows teachers to develop advanced skills that will be very useful also in post-covid teaching and to reflect deeply on how to rethink teaching practices and methodologies. The training phase will also include an advanced training phase on specific topics (such as learning object design, use of OER-Open Educational Resources, Learning Analytics, etc.) for teachers who have been participating in the project for many years and use the online teaching in their daily teaching. In this paper we present the analysis phase of the teachers' needs and the support and training phase. As the results show, the participation of the teachers (new members of the project and not) was high and there was a lot of collaboration on the platform between the teachers and between teachers and trainers, especially between teachers already enrolled in the project for a long time and teachers who had just registered. At the end of the school year, all teachers will receive a certification of all the training activities in which they participated and a certification of all the activities carried out on the platform. The activities carried out by the teachers in online teaching and the participation of the students will also be analysed in detail to understand the activities and resources that proved most effective and engaging. Further considerations will also be taken on online teaching and on the change of the school during the emergency, on the proposed training activities, on the repercussions that online teaching had on students and their comments. In the paper we discuss why and how the PP\&S project was able to immediately detect the needs and play an important role of 
Fissore, C., Marchisio, M., \& Rabellino, S.

Secondary School Teacher Support and Training for Online Teaching during the COVID-19 Pandemic

immediate support and useful training for the change of paradigms to which the teaching will be subjected.

Table 4: $\quad$ General overview of the PP\&S project, last update May 27, 2020

\begin{tabular}{|c|c|c|c|}
\hline & Amount & & Amount \\
\hline Users & 26037 & $\begin{array}{l}\text { New users AY } \\
2019 / 2020\end{array}$ & 4386 \\
\hline $\begin{array}{l}\text { of which } \\
\text { teachers }\end{array}$ & 1842 & of which teachers & 402 \\
\hline $\begin{array}{l}\text { of which } \\
\text { students }\end{array}$ & 24195 & of which students & 3984 \\
\hline
\end{tabular}

\section{Online teaching in an integrated Digital Learning Environment}

Distance learning and online teaching are not the same thing. Online teaching, not only during this emergency period, should not be a mere transfer of face-to-face lessons in synchronous online mode via web conference. Here are several reasons why: it is very difficult for students to stay in front of a screen for many consecutive hours; students are not necessarily able to connect due to slow or overloaded home internet connections (digital divide); large families do not necessarily have a device for each family member and there may be organizational problems; there may be privacy problems related to the desire of not using the webcam; there may be technical difficulties in getting students to work (for example in the absence of a blackboard); there may be economic problems in the family to guarantee one or more mobile devices and an adequate internet connection; it is more difficult to stay focused on the lesson and concentrated for a long time outside the school context and in a private context with many distractions. At the same time, online teaching cannot consist of a simple transmission of materials and tasks and exercises. Online teaching is a form of teaching that consists of resources but also and above all asynchronous activities that are always available, which students can carry out when they can and when they prefer. In fact, online learning allows students to study from home respecting their own times and independently organizing the time schedule of the study. It is certainly necessary that the didactic proposals are, as always, built on quality content and that they are structured in a precise way, considering the students' previous knowledge. Resources and activities can be multimedia and can be the result of the integration of different media to facilitate students' understanding and personalization based on each person's characteristics. A fundamental component for Online Teaching is the DLE, an online space shared between teacher and students for the availability and use of training (Rogerson-Revell, 2007). The DLE of the PP\&S is based on a Virtual Learning Environment, VLE, a Moodle-learning platform, integrated with an ACE, that is Maple (www.maplesoft.com), an Automatic Assessment System (AAS) and a web conference system. The innovative methodologies proposed by the PP\&S project are: problem posing and solving using an ACE that supports problem formulation, presentation, resolution and 
generalization, and that allows the creation of interactive materials (Barana et al., 2019; Barana, Conte et al., 2019a); automatic formative assessment with adaptive questions aimed at teaching students how to solve problems, guiding them step-by-step with interactive feedback in the solving process, through an ACE and an AAS (Barana et al., 2020; Barana, Conte et al., 2019b).; collaborative learning among teachers in a community of practice for the exchange of ideas, strategies and materials (Barana et al., 2018); collaborative learning among students in a learning community. It is important to underline that the term "Online Teaching" does not only mean the virtual environment for the synchronous interaction between users (videoconference, chat and so on) but also the asynchronous learning (which does not require the presence of users at the same time). Within the DLE it is possible to deliver multiple types of resources such as videos, interactive files, pdf files, conceptual maps, links to external sites, collection of images and photos, podcasts, etc. Students can view the contents created with the advanced computing environment directly within the DLE and explore them interactively. This type of material is very valuable for STEM disciplines because it allows to view and explore mathematical situations (even with two and three dimensional and animated graphics) to study concepts effectively, to develop problem solving skills (and generalization of the solution process), and to develop modelling skills. Within the DLE it is also possible to create multiple types of synchronous and asynchronous activities: discussions, tests with automatic assessment, submission of tasks, sharing of materials, workshops, questionnaires, surveys, logbook, etc. Quizzes can have questions with automatic assessment and with interactive and immediate feedback. This type of questions allows students to carry out the necessary exercises independently, to have step-by-step guided solutions to learn a method, and to make repeated attempts of the same exercise with different parameters and values. This activity promotes students' autonomy and awareness of their skills and facilitates class management for teachers. All activities within the DLE can be carried out alone or in a group and support students' collaborative learning. As stated before, all activities can be evaluated: by the teacher, by the student himself (self-assessment) and by the other students (peer evaluation). All teachers enrolled in the PP\&S can request the opening of one or more courses on the platform to work with their students and through the helpdesk service they require the accreditation of the students on the platform. Each user of the platform can open a ticket to the helpdesk service at any time to get support for access problems, to get information or help in using the platform. Teachers can customize their DLE as they prefer and design the activities and resources for the students. Within the Teacher Community, which includes teachers from all over Italy enrolled in the project, there are many materials for self-training (interactive materials, training modules, video pills, pdf, etc.) and database of materials for sharing between teachers. The sharing of teaching material is the basis of the project, as well as the sharing of ideas, good practices and teaching methodologies through forums. 


\section{Analysis of needs and considerations on online teaching during the covid-19 emergency}

To analyse the needs of the teachers during the emergency period, an optional questionnaire inside the DLE was submitted to the teachers to understand if the teachers had already practiced online teaching, if the teachers had already used the new technologies, and which activities and resources they consider most useful for their teaching. We also asked to express their thoughts and experiences on their teaching in the covid-19 time and how their experience was within the PP\&S platform. The needs survey showed that $48 \%$ of the teachers already practiced online teaching even before the emergency and $90 \%$ of the teachers used the technologies for teaching even before the emergency. $44 \%$ of teachers have been enrolled in the PP\&S for less than 3 months (enrolled during the emergency), 10\% of teachers have been enrolled for more than 5 months and for less than a year, $12 \%$ have been enrolled for two years and $34 \%$ have been enrolled for 3 years or more. The teachers were asked how important they consider various tools related to online teaching with students, expressing a score on a scale from $1=$ not at all to $5=a$ lot. According to teachers all the tools are important, but the most significant ones are video conferencing (to be able to communicate with students and deal directly with them), interactive resources and tests with automatic assessment. The teachers were also asked how much they agree on several statements regarding online teaching with students (on its effectiveness, on the participation of students, etc.) by expressing a score on a scale from $1=$ not at all to $5=$ a lot (Table 2 ). Most teachers agree that effective online teaching is also possible and that this type of teaching stimulates the development of additional skills in students. The teachers also agree on the need to have material available and to receive more training.

\section{Teacher support for online teaching during the covid-19 emergency}

At the end of the needs analysis and the analysis of the teachers' considerations, a first phase of support for the teachers was prepared, in the delicate moment of approach to online teaching and first knowledge of the tools. To respond to the most immediate needs and to offer support as quickly and effectively as possible, the following actions have been implemented: three weekly online synchronous meetings lasting one and a half hours (in some cases repeated) with a part of explanation and a part dedicated to answering questions. The meetings focused on several topics such as the use of the DLE, the automatic assessment system, the design of collaborative activities; forum to be able to express any doubts and receive an immediate response; enhancement of the Helpdesk service and email management to answer promptly to all requests; enhancement of the database of ready and available materials; enhancement of self-training material (always available to teachers). 
Table 2: Reflection by teachers on the importance of online teaching tools with students

\begin{tabular}{ll}
\hline Online lesson preparation takes longer than face-to-face lessons & 4.4 \\
Online teaching stimulates the development of additional skills in students & 4.2 \\
Teachers would need resources available for online teaching & 4.2 \\
Teachers would need more support for online teaching & 4.1 \\
Online teaching should also be used in ordinary teaching & 3.9 \\
The participation of my students from home is active & 3.8 \\
\hline
\end{tabular}

All these actions offer basic literacy and initial training; very practical and directly usable. In this phase it was essential for the teachers to have constant support from the tutors and to share teaching practices and advice between the teachers of the community. In addition, online extracurricular activities were organized for students to increase their engagement: a mathematical competition on Pi Greco Day and disclosure of materials and quizzes on Dante Day. This support phase actively involved about 200 teachers during synchronous online meetings, but many more teachers on the platform in the teaching community. Table 3 shows data about users in the PP\&S between the period Pre Covid-19 (01/09/2019 - 29/02/2020) and during Covid-19 (01/03/2020 to the present date, written in the table caption). These numbers do not only show an increased access to the platform, but they also indicate active engagement and collaborations in the Community of Teacher forum. The collaboration of the teachers on the platform to overcome this emergency was particularly important and significant. The teachers discussed a lot about how to best propose an online teaching, to carry out synchronous online lessons and how to prepare relevant materials and resources. The teachers collaborated mainly through the forum of the Teacher Community (Table 4), where each teacher can open a discussion, write an intervention in a discussion already present or simply consult the forum. The ever-present support of the trainers was also fundamental. The statistics about the usage of the whole platform (Table 3) show a significant increase which proves the effective utilization of the e-learning tools.

Table 3: $\quad$ Comparison between Pre and During Covid-19, last update May 28, 2020

\begin{tabular}{lrrrr}
\hline & Pre Covid-19 & During Covid-19 & Increase \\
\hline Period & $01 / 09 / 2019-$ & $\begin{array}{r}01 / 03 / 2020 \\
\text { dap to }\end{array}$ & \\
& $29 / 02 / 2020$ & 2924 & $+199 \%$ \\
\hline New users & 1466 & 38 & $+239 \%$ \\
Average of new users per day & 11 & 8418 & $+73 \%$ \\
Average login per day & 4875 & 1289 & $+1001 \%$ \\
Average distinct user login per day & 117 & 3199 & $+853 \%$ \\
Educational resources created & 375 & 2778638 & $+1739 \%$ \\
Educational online activities performed & 159773 & 4266 & $+262 \%$ \\
Grades received by students & 1630 & & & \\
\hline
\end{tabular}


Fissore, C., Marchisio, M., \& Rabellino, S.

Secondary School Teacher Support and Training for Online Teaching during the COVID-19 Pandemic

Table 4: Data from the Teacher Community forum Pre and During Covid-19, last update May 28,2020

\begin{tabular}{lrr}
\hline & Pre Covid-19 & \multicolumn{1}{c}{ During Covid-19 } \\
\hline Period & $01 / 09 / 2019-29 / 02 / 2020$ & $01 / 03 / 2020$ up to date \\
\hline Threads created & 77 & 128 \\
Threads read & 2203 & 2877 \\
Posts created & 179 & 318 \\
\hline
\end{tabular}

All the teachers have transformed their teaching into online teaching, structuring the course on the platform and inserting different types of activities and resources for the students. At this stage, the help of the most experienced teachers was certainly very important, in fact they gave valuable advice and constant help to colleagues who had just entered the project. A free online webinar on online education was also organized within the project, open to all interested people (teachers and non-teachers) organized in collaboration with the "Ragazzi Connessi" Project of Genoa. Lastly, we would like to underline that the IT infrastructure was not adapted in response to the new users load in any way: the high-performance and high availability solution (Baldoni et al., 2011) adopted for the PP\&S service was able to serve the bigger numbers without affecting the user experience.

\section{Teacher training for online teaching during the covid-19 emergency}

Starting from the month of May, when most of the teachers were regularly teaching online, a phase of teacher training began (still in progress). The objective of this phase is to offer training that allows teachers to develop skills also from a post-covid perspective, to rethink their teaching in order to integrate online teaching into their future face-to-face teaching or to practice blended teaching. It is particularly important to reflect on how new technologies can allow adaptive learning, thus supporting students' cognitive processes, increasing their involvement and allowing the inclusion of the most disadvantaged or disabled students (Erik Duval, 2017). First, a training module was proposed to the teachers, consisting of: 4 one-hour synchronous online meetings on important topics: the design of the virtual classroom environment; activities and resources for students' collaborative learning; online formative assessment, self-assessment and peer evaluation; adaptive strategies for personalized teaching and for monitoring the learning processes; creation by teachers of multimedia material for learning a specific topic; creation by teachers of an activity for assessment or collaborative learning; documentation on how the resource and the activity created are used by students. The training module will end in June, but training activities will also continue. At the end of the school year, additional questionnaires will be offered to teachers to collect thoughts on online teaching in the emergency period and on its impact on students. 


\section{Conclusions}

After a first phase of needs analysis, the emergency evolved in a broad-spectrum training action: in a first phase of digital literacy for teachers and in a second, more advanced training phase. Both phases are characterized by the teacher's ideas on the necessary change of perspective about teaching during this emergency. As the results show, the participation of teachers in the training activities and the collaboration among teachers on the platform were relevant. Post-covid teaching will probably be a much more blended teaching (in attendance but also online). Doing online teaching now definitely allows teachers to acquire new skills and to prepare teaching materials that can be used in future teaching. Online teaching should be understood as an additive and not a substitute paradigm for classroom teaching. The teachers of the PP\&S will certainly have an advantage and will be able to take advantage of the work done and the experience and skills gained. At the end of this school year, the activities carried out by the teachers and the participation of the students will be analysed in detail in order to understand the activities and resources that proved most effective. Further investigations will also be carried out on teachers and their students on online teaching during the emergency and on the use of the platform. Such a strong action of supporting and training to teachers of the secondary school was made possible because the PP\&S was an already consolidated reality that in the emergency has expanded its range of action in order to turn an emergency into an opportunity for the future.

\section{References}

Baldoni, M., Cordero, A., Giraudo, M., Grandi, C., Rabellino, S. (2011) HAP-Moodle: una soluzione open-source per l'High-Availability e la performance applicata a Moodle. Elearning con Moodle in Italia: una sfida tra passato, presente e futuro. Seneca Edizioni, 213-226.

Barana, A., Brancaccio, A., Conte, A., Fissore, C., Floris, F., Marchisio, M., \& Pardini, C. (2019). The Role of an Advanced Computing Environment in Teaching and Learning Mathematics through Problem Posing and Solving. Proceedings of the $15^{\text {th }}$ International Scientific Conference ELearning and Software for Education, 2, 11-18.

Barana, A., Brancaccio, A., Esposito, M., Fioravera, M., Fissore, C., Marchisio, M., Pardini, C., \& Rabellino, S. (2018). Online Asynchronous Collaboration for Enhancing Teacher Professional Knowledges and Competences. The $14^{\text {th }}$ International Scientific Conference ELearning and Software for Education, 167-175.

Barana, A., Conte, A., Fissore, C., Floris, F., Marchisio, M., \& Sacchet, M. (2019a). The Creation of Animated Graphs to Develop Computational Thinking and Support STEM Education. In Maple Conference (pp. 189-204). Springer. 
Barana, A., Conte, A., Fissore, C., Marchisio, M., \& Rabellino, S. (2019b). Learning Analytics to improve Formative Assessment strategies. Journal of e-Learning and Knowledge Society, 15(3), 75-88.

Barana, A., Fissore, C., \& Marchisio, M. (2020). From Standardized Assessment to Automatic Formative Assessment for Adaptive Teaching. Proceedings of the $12^{\text {th }}$ International Conference on CSEDU, 1, 285-296.

Erik Duval. (2017). Technology enhanced learning: Research themes. Springer Science+Business Media.

Rogerson-Revell, P. (2007). Directions in e-learning tools and technologies and their relevance to online distance language education. Open Learning, 22(1), 57-74. 